\title{
Physical and mechanical properties of membrane Polyacrylonitrile
}

\author{
Agung Mataram ${ }^{1, *}$, Syahrul Nasution ${ }^{1}$, Mazari Legi Wijaya ${ }^{1}$, Gurruh Dwi Septano ${ }^{1}$ \\ ${ }^{1}$ Mechanical Engineering Department Engineering Faculty Universitas Sriwijaya, 30662 Inderalaya, Indonesia
}

\begin{abstract}
Tensile test is a method used to measure the strength of a material by providing the burden of the opposing forces in a straight line. This experiment used to measure a material's mechanical strength against a static force which is given slowly. This study discusses on the tensile strength polyacrylonitrile (PAN) membranes made in three variations of the specimen with a mixed composition of different PAN $15 \%, 17.5 \%, 20 \%$, in weight). The membrane was created using Sigma Aldrich Polyacrylonitile of polymer fibers and N,N-Dimethylformamide (DMF) as solvent. The process began by mixing the two materials using a magnetic stirrer for 6 hours until the solution is assumed to be homogeneous. The solution wass stored in the bottle airtight and allowed to stand for 24 hours for the next printing. The membrane was keep in storage in tubes desiccator until its water content reduced, then the test can be done. In this study, a machine adhesion terring strength tester was used conducting Strength Test at a speed of $5 \mathrm{~mm} / \mathrm{min}$. The test results showed an increase in the value of $359 \mathrm{kPa}$ on the composition of $15 \%, 473 \mathrm{kPa}$ on the composition of $17.5 \%$, and $653 \mathrm{kPa}$ for the composition of a mixture of $20 \%$.
\end{abstract}

\section{Introduction}

Microbiological contamination of some water sources that exist at the moment is very worrying to the public, according to some researchers, there are many different species of bacteria which are available in pure water and wastewater [1,2].

This application requires a membrane that can improve water quality. The membrane is a layer formed from the composition or the tangle of fine fibers used as filter or barrier for a variety of applications in the industrial world. polymer has been the material of interest to be analyzed and developed its potential as a membrane filter, application examples that are of concern at this time is a membrane filter water [3].

The main objective to be achieved in this discussion are:

- To develop a new method in the production of membrane

- To determine the mechanical properties of the membrane of polyacrylonitrile (PAN) against tensile testing

The membrane is a layer formed from the composition or the tangle of fine fibers used as filter or barrier for a variety of applications in the industrial world.

PAN is one of the versatile polymers that is commonly used for producing membranes due to its good solvent resistance property [10]. Membrane polymer produced using Polyacrylonitrile as fiber polymer and DMF as a solvent, the process of printing the membrane by the method of a flat sheet, the membrane of this type is typically used in ultrafiltration process, due to higher porosity and pore structure are interconnected, resulting in permeability is higher for water filtration [4].

Characterization of membrane was conducted to determine the properties of the membrane resulting from any research, this method will provide information on the extent to which efficiency and effectiveness can be obtained from the membrane that has been made, a technique that can be used to determine the characteristics of the membrane there are a number of ways, but a common used permeability and permeselectivity.

\section{Methodology}

\subsection{Membrane preparation}

Dominated by carbon fiber, Polyacrylonitrile fibers due to a combination of the polymer, has good mechanical properties, especially tensile strength [3].

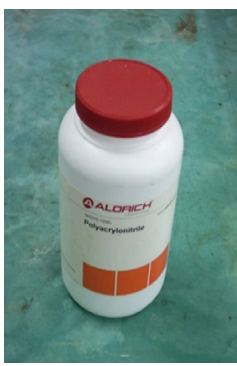

(a)

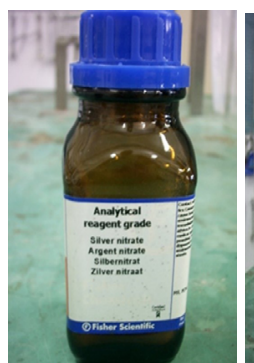

(b)

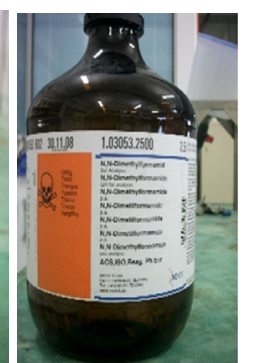

(c)
Fig. 1. (a) Polyacrylonitrile (PAN), (b) Silver Nitrate, (c) N,N-Dimethylformamide

\footnotetext{
*Corresponding author: amataram@unsri.ac.id
} 
The advantage of the PAN fiber, high degree of molecular orientation and a higher melting point (PAN fiber tends to decompose below the melting point, Tm of $317-330^{\circ} \mathrm{C}$ ), and the results were better than carbon fiber [5]. Polyacrylonitrile used (Figure 1a). Generally, carbon membrane is known by its amorphous porous structure created by the evolution of gases generated during pyrolysis of the polymeric precursor [10].

Polyacrylonitrile can form a thermally stable molecular structure of highly oriented while getting a low temperature heat treatment, which is not significantly impaired during treatment carbonization at a higher temperature, this means the fibers produced have excellent mechanical properties $[6,7]$.

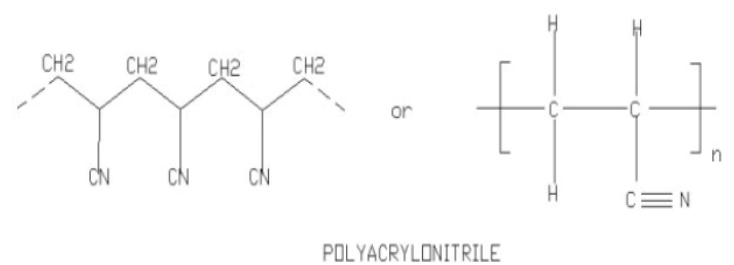

Fig 2. The molecular structure of polyacrylonitrile [10]

Silver is a chemical element in the periodic table that has the emblem of Ag and atomic number 47. arms is derived from the Latin Argentum. A transition metal is soft, white, shiny, silver has the highest electrical conductivity and heat throughout the metal and there dimineral and in free form. This metal is used in coins, jewelry, equipment tables, and photography. Silver including precious metals such as gold [8].

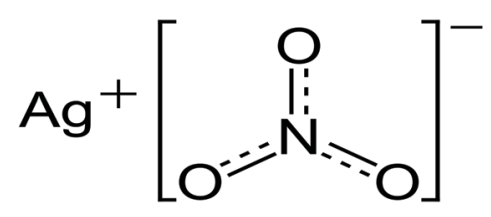

Fig. 3. Molecular Structure of Silver Nitrate

Chemical Properties Silver Nitrate (Fig 3):

- Very stable in pure air and water so it does not react with air and water at normal temperature.

- Less reactive than copper, except ozone, sulfur and hydrogen sulfide, which is rapidly discolor the silver surface.

- Not soluble in dilute acid solution, but can be dissolved in nitric acid and sulfuric acid.

- Silver and silver compounds are all soluble cyanide as the alkali metal ion $\mathrm{Ag}(\mathrm{CN}) 2$ in the free air, which is then released by adding zinc silver or aluminum as reluctant.

- Anion can precipitate as most anions forming insoluble silver salts. For example, the addition of the $\mathrm{Ag}+\mathrm{OH}$ - will precipitate silver (I) oxide.

$$
2 \mathrm{Ag}_{(a q)}^{+}+2 \mathrm{OH}_{(a q)} \rightarrow \mathrm{Ag}_{2} \mathrm{O}_{(s)}+\mathrm{H}_{2} \mathrm{O}
$$

N,N-Dimethylformamide (DMF) supplied by MERCK (figure 4) and is used as a solvent without further purification, this is a strong solvent for PAN polymer, because they have desirable properties such as low volatility, non-flammable, and relatively low toxicity.

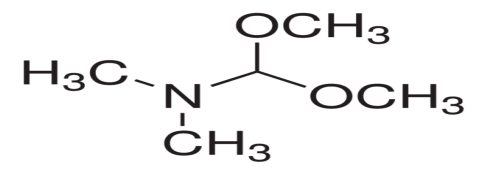

Fig. 4. N,N-Dimethylformamide

\subsection{Preparation of Polymer Membranes}

Membranes made in this study were conducted with two materials with different variations of the mixture on each specimen, materials used is PAN and DMF. The mixing of the two materials using a Magnetic Stirrer, this tool will mix the two ingredients with the rotation system so that the mixture becomes homogeneous [9].

Methods flat sheet is one way in the process of making the membrane author uses glass plates and duct tape as a template membrane, membrane PAN prepared by phase inversion method immersion in a tub of coagulation of water, the result of printing membranes with these methods form a flat sheet [9]

Tensile test is a method used to test the strength of a material by providing load coaxial style. This experiment used to measure the mechanical strength of a material is the force of static given slowly, the results of tensile testing is essential to engineering and product design for yield strength data material tensile testing done to complete the design information is basic mechanical strength of a material and as a data support for material specifications.

The purpose of tensile or mechanical testing is to measure the effect of force on a particular material or component, or on the adhesive or fastener that bonds two materials together.

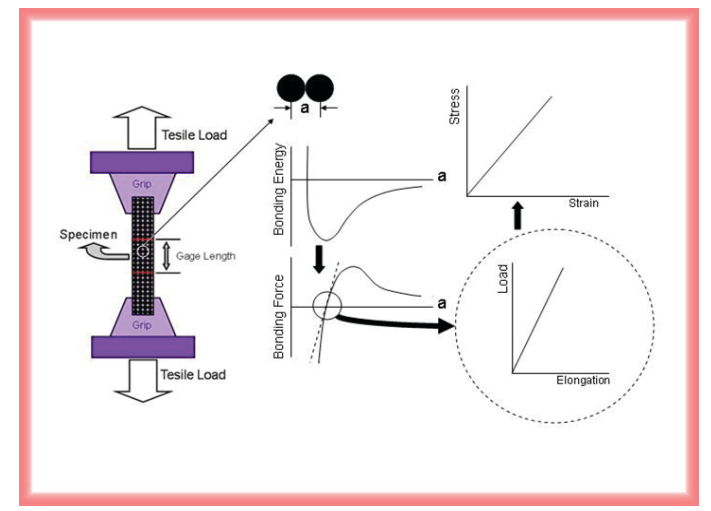

Fig. 5. Schematic of Tensile Test [ souce: etomica ]

As seen in Fig 5, the specimen material is pulled by tensile load at a constant rate until it fractures. During the test, the tensile load and the elongation of 
the gage length of the specimen are monitored and Microstructure Test tool SEM (Scanning Electron Microscope), which uses an electron microscope. SEM testing is done in stages on each membrane composition. Scanning Electron Microscopy (SEM) has been used to investigate the resultant membrane morphology [10].

SEM testing is used to view and analyze surface and texture, shape and size of objects to analyze the sample and analyze the composition of the surface of objects both quantitatively and qualitatively. At this time, through the SEM Test, the size of the pores can be performed. The voids or holes in the membrane and the bond that exists every pore in the membrane were detected as well.

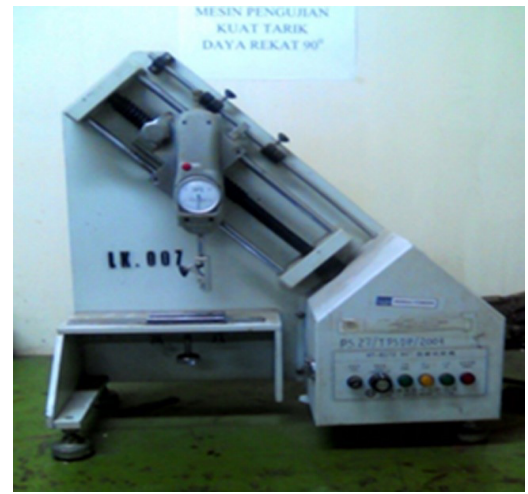

Fig. 6. Adhesion Tearring Strenght Test

The test in this research conducted procedure comprising the steps the steps below:

- Preparation of the membrane material,

- Polyacrylonitrile and N, N Dimethylformamide.

- Prepare materials stirrer (magnetic stirrer).

- Considering mixture of PAN and DMF prior to the

- mixing process takes place.

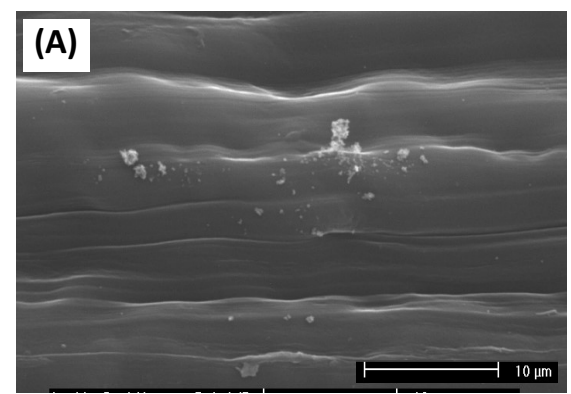

recorded.

- Stir the two ingredients for 6 hours under on each specimen

- Print the membrane solution that has been homogenized using glass mold that has been provided.

- Prepare a tensile testing machine tearing adhesion strength test (Figure 6). After that perform appropriate testing procedures

- Prepare test equipment SEM, once ready to do appropriate testing procedure.

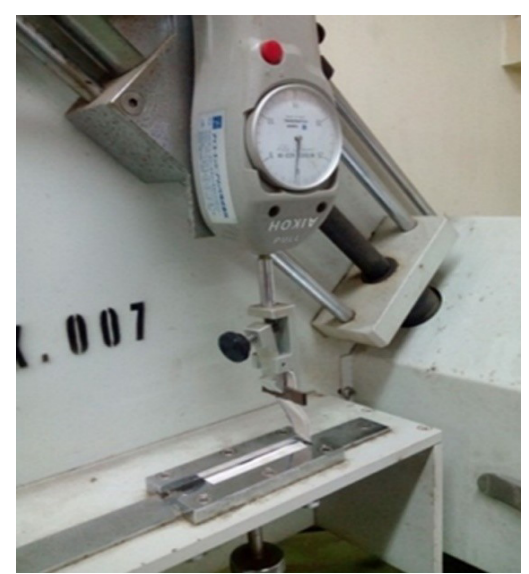

Fig. 7. Process polyacrylonitrile membrane tensile testing

\section{Result and discussion}

In the current work, the test results show the mechanical properties of the PAN membrane material, each specimen using a membrane tensile testing machine tearing adhesion strength test (as seen in Fig. 7).

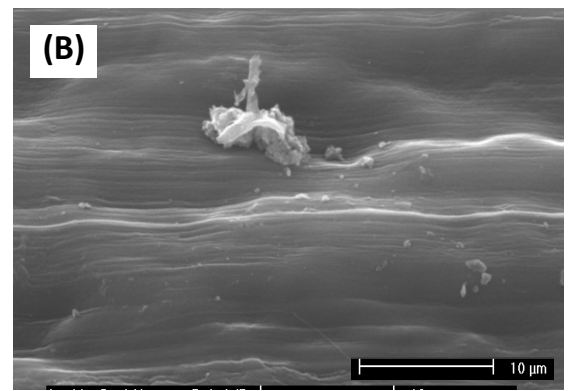

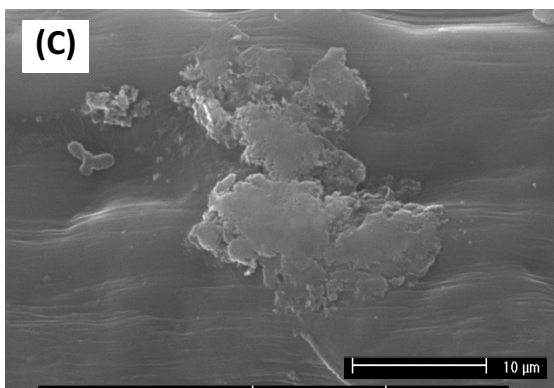

Fig. 8. SEM comparison PAN fibers with different variations (A) $20 \%$ by weight, (B) $17.5 \%$ by weight (C) $15 \%$ by weight. 
This test is generally aimed to determine the mechanical properties of a material. Specifically in this study, the tensile resistance of the membrane is also evaluated. The additional results was also collected with some test using Scanning Electron Microscopy (SEM).

The results SEM micrograph of the surface of PAN fiber is shown in Fig.8, when the PAN fiber content is at $17.5 \%$ and $20 \%$, PAN nanoparticle dispersions relatively simple homogeneous, but with the added amount (\%. PAN) in a solution with a composition of $20 \%$, occur agglomeration excessive resulting solution is more difficult to be homogeneous $[10,11]$.

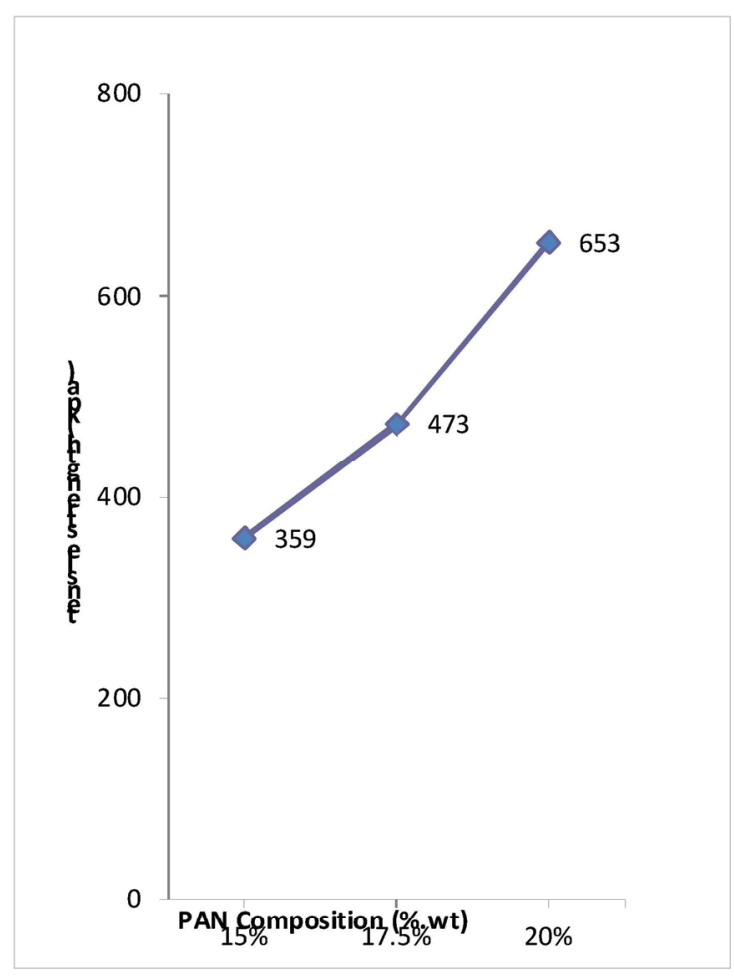

Fig 9. The tensile strength (A) of the PAN composite fiber with changes in the composition ( $\% \mathrm{w}$ of PAN) on each specimen.

Tensile test specimens were having a composition respectively $15 \%, 17.5 \%, 20 \%$ PAN. The tensile strength of the specimens showed increases in the value of $359 \mathrm{kPa}$ to $600 \mathrm{kPa}$ when the specimen with a composition of PAN fiber increased from $15 \%$ to $17.5 \%$, the value of the tensile strength of the fiber membranes with composition (weight \%) 20\% PAN also showed an increase up 653Kpa.

The rising value of the tensile strength of the membrane of $359 \mathrm{Kpa}$ to $653 \mathrm{kPa}$ is due to the increase amount $(\% \mathrm{w})$ of PAN on each specimen. It may caused by fiber braid structure of the membrane which is increasingly interacted [12].

\section{Conclusion and suggestion}

\subsection{Conclusion}

Based on the research results polyacrylonitrile membrane tensile testing, as described, it could be concluded as follows:

- The length of time and the rotation speed of the mixing process of membrane material influence on the results of the homogeneity of the membrane solution.

- The temperature at the time of stirring is also important to remove residual solvent and trapped air that can cause bubbles on the membrane

- Results of testing the best there is in the composition of $20 \%$ PAN because it can withstand loads of up to $824 \mathrm{kPa}$.

\subsection{Suggestions}

- To obtain a more accurate tear resistance are advised to set clamp arm so that when the testing took place the specimen is not moving, because if it moves, then the result would be different and affects the outcome of the cycle.

- Once the membrane is printed should be immediately placed in a tube desiccator until its water content is reduced, when no water should remain immersed in the coagulation so that the membrane does not become brittle thus reducing capable mechanic of the membrane itself.

- In SEM testing, to obtain better results SEM electricity entering the SEM tool must be stable and at the time of testing in order to cut into small pieces and flat membranes and flat. After that do plating / coating on non-conductive specimens in order to study the morphology of the membrane that is clearly visible.

\section{References}

1. Bonnélye, V., Gueya, L. and Del Castillo, J, Desalination. 222, 59-65, (2008)

2. Mulder, M. Basic Principles of Membrane Technology. ( $1^{\text {st }}$ ed.) London: The Netherlands, Kluwer Academic Publisher. (1991)

3. Masuelli, M.A.. INTECH. Chap 1. (2013)

4. Thavasi, V, Singh, G. and Ramakrishna, S. Energy and Environmental Science. 1, 205-221, (2008)

5. Fitzer, E. and Manocha,L. M,. Carbon Composites (Ch. 1). New York: Springer-Verlag. (2007)

6. Donnet, J. B. and Bansal,R. C, Carbon Fibres. Marcel Dekker: New York. (1984)

7. Schindler, E. and Maier,F. US Patent 4919860. Washington: U. S. Patent and Trademark Office, (1990)

8. Goldman, G, Starosvetsky, J. Armon, R, Journal Membrane Scence. 341, 145-152. (2009)

9. Mataram, A., Ismail, A.F., Yuliwati, Y., Matsuura, T., Zamheri, A., Rizal, S. Application of Electrospun Nanofibers. 77:1, 263-267. (2015) 
10. Saufi, S. M., Ismail. A.F,. Journal of Science and Technology. 24, 843-854, (2002)

11. Sri Aprilia et al. Report. Jurusan Teknik Kimia, Fakultas Teknik, Universitas Syah Kuala. Banda Aceh (2003)
12. Yoneyama, H. and Nishihara. Y, US Patent 0494449. Washington: U. S. Patent and Trademark Office, (1990) 